\title{
netz:regeln 2015: Digital Everything - Wie digital ist unsere Zukunft?
}

\section{Am 26.11.2015 veranstalten der Bitkom und die Heinrich-Böll-Stiftung gemeinsam die Konferenz netz:regeln 2015 in Berlin. Veranstaltungsort ist die Heinrich-Böll-Stiftung, Schumannstraße 8, in Berlin. Beginn ist um 10:00 Uhr das voraussichtliche Ende um 15:00 Uhr.}

Heute sprechen wir von Industrie und Arbeit 4.0, dem Internet der Dinge, prognostizieren die Mensch-Maschine und diskutieren Chancen und Gefahren der Digitalisierung. Doch was wissen wir schon jetzt darüber, wie unser Leben im Jahr 2025 wirklich aussehen wird? Was können wir aus früheren Prognosen lernen? Welche Visionen sind realistisch, wie schnell werden die Veränderungen in Gesellschaft, Wirtschaft und Arbeitswelt eintreten? Welche Strategien verfolgt die Politik, welche Potenziale kann sie heben? Diese Fragen werden Vertreter aus Wissenschaft und Forschung, Netzgemeinde, Politik und digitaler Wirtschaft in Berlin aufgreifen und diskutieren. Sie werden mehr darüber erfahren, wie digital unser Leben in zehn Jahren wirklich sein wird. Was bleibt von manchen Trends übrig, welche Entwicklungen werden dagegen gar übersehen?
Mit netz:regeln 2015 laden der Bundesverband Informationswirtschaft, Telekommunikation und Neue Medien e.V. (Bitkom) und die Heinrich-Böll-Stiftung e.V. zum sechsten digitalpolitischen Dialog ein.

Die Themen:

- Digitale Demokratie 2025: Wie können Politik und Verwaltung die digitale Transformation mitgestalten?

- Altes Europa 2025: Wie erreichen die deutsche und die europäische Wirtschaft digitale Souveränität?

- Digitale Öffentlichkeit(en) 2025: Wie kommunizieren wir in zehn Jahren?

- Smart Data 2025: Was können Daten in zehn Jahren?

Das detaillierte Konferenzprogramm finden Sie auf der Website des Bitkom: www.bitkom.org.

Der Eintritt ist frei, um Anmeldung wird gebeten.

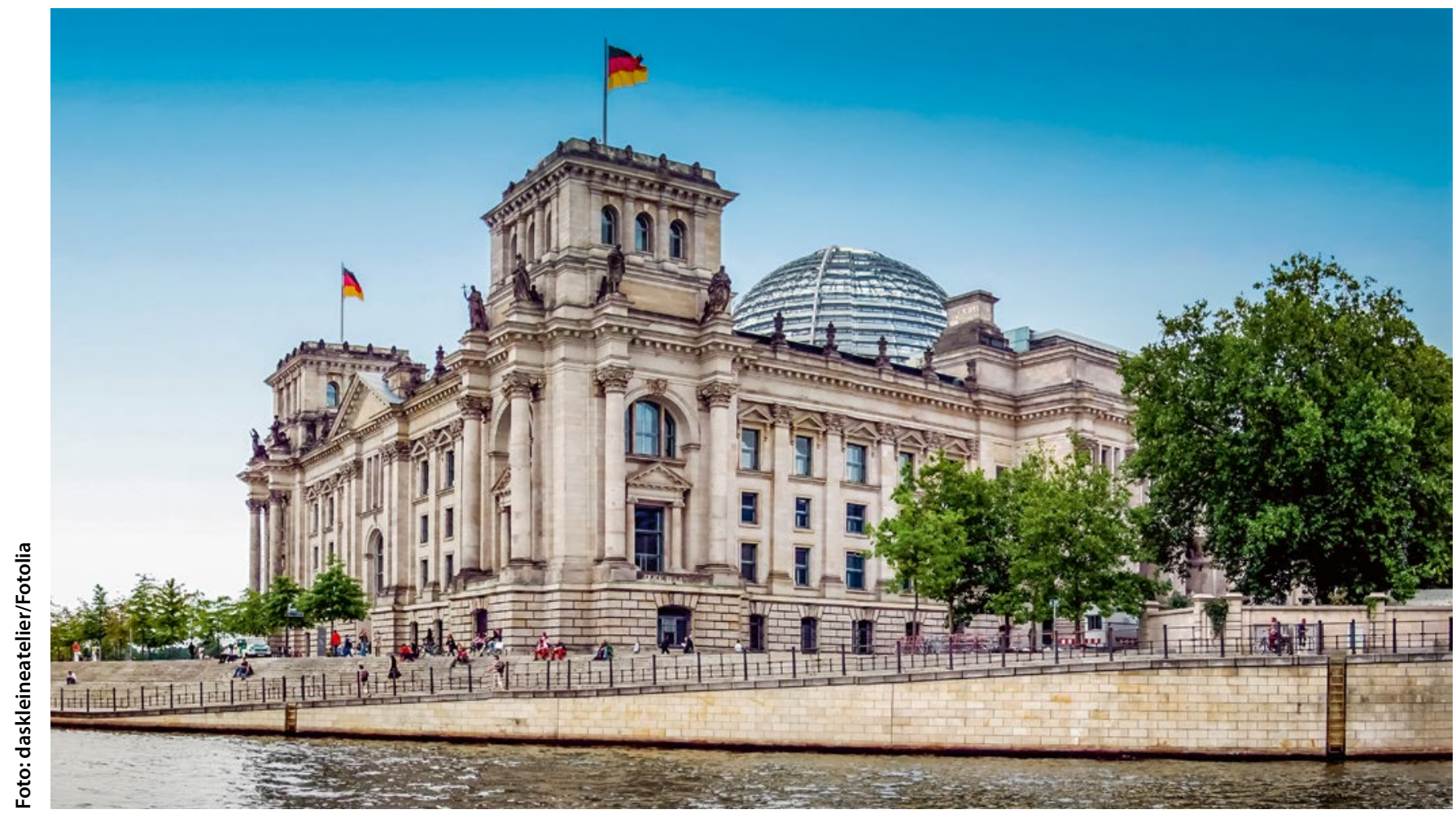

